http://bjas.journals.ekb.eg

\title{
Late results after anterior cruciate ligament rupture reconstruction
}

\section{E.H.Abdelmagid, S.A.Al Traigy, M.El Ashhab and M.O.Hegazy}

Orthopedic, Dept., Faculty of Medicine, Benha Univ., Benha, Egypt

Email:Emad@gmail.com

\section{Abstract}

ACL injuries are very frequent in sports medicine. This research set out to comprehensively evaluate the existing research on late outcomes in the wake of ACL repair. From the beginning until April 2020, all Medline searches have been conducted using PubMed, SCOPUS, Web of Science, Cochrane Central Register of Controlled Trials (CENTRAL), and Google Scholar. 2089 distinct records were found during the search. We were left with 57 possibly suitable records, of which we did full-text searching on all of them. The final count was twelve studies. After ACLR, the long-term rate of Lachman Grade 0-1 was estimated to be 97.8 percent (95 percent confidence interval: 196-99.5 percent). This figure shows that, although on the one hand, the long-term average of Pivot Grade 0-1 after ACLR was 97.8 percent (95 percent CI 96- 99.5 percent), the effect estimates indicate that the long-term average rate of Pivot Grade 0-1 after ACLR was only 95.3 percent (95 percent CI 95.2- 95.5 percent). IKDC score A rate was $55.4 \%$ (95\% CI 42.7-68.2\%). The Lysholm mean score was 84.4 (95\% CI: 84.4 to 84.4). The failure rate in the current research varied between 0 and $10 \%$, whereas the complication rate ranged between 8 and $11 \%$. Meniscal operations, notchplasty, irrigation, and debridement were most frequent complications. A total of 12 investigations revealed that Lachman Grade 0-1 (most severe) after ACLR results in a 97.8 percent success rate, and Pivot Grade 0-1 (most severe) after ACLR results in a 97.8 percent success rate. Prior to surgery, the Lysholm score had been at an insufficient level.

Keyword: ACL, Rupture, Reconstruction.

\section{Introduction}

Osteoarthritis accelerates as a result of an ACL rupture, one of the most frequent knee injuries. The good news is that ACLR is effective in helping patients return to high-level sports and hard work. The bad news is that ACLR does not help to maintain and improve movement.

The ACL's intricate structure illustrates its major role in knee joint mobility. Originally referred to as a cruciate ligament, because the anterior and posterior ligaments are organised into two criss-cross patterns on the anterior and posterior portions of the knee. In reference to the ACL femoral attachment, the lateral portion of the ACL is positioned on the posterior side of the medial surface of the lateral femoral condyle, and is directed along the longitudinal axis of the femur when the knee is extended.

The ACL is crucial for proper knee flexion, rotation, and stability. Anterior translation of the tibia on the femur is heavily restrained by the ACL, and internal rotation, varus, valgus, and hyperextension are also restrained. Posterior drawer will still be applied once the ACL has been deployed. There is a substantial increase in anterior knee instability after sectioning the ACL. Approximately $15^{\circ}$ to $45^{\circ}$ of anterior translation is seen when solo ACL reconstruction is completed.

ACL injuries are a common injury for this knee ligament. While less common, ACL injuries often afflict younger, more active people, and females are believed to be around two to ten times more likely to be injured than men.

In the treatment of ACL ruptures, many clinical tests may be utilised. According to pooled studies, the Lachman test has a sensitivity of $85 \%$ and a specificity of $94 \%$. Sensitivity and specificity for chronic ACL ruptures (anterior drawer test, 92 percent) are excellent, while accuracy for acute ruptures is lower (91 percent). The pivot shift test is unequivocal evidence of an ACL rupture when positive (98 percent specificity). A negative test does not exclude the possibility of harm (24\% sensitivity).

To make a diagnosis of an ACL rupture, the combination of patient history and physical examination is typically enough. However, it may be difficult to notice the damage during clinical examination if there is severe pain and effusion. Misdiagnosis is very frequent; of the patients who were evaluated for an ACL tear in an orthopaedic emergency room, $50 \%$ were given a non-ACL injury diagnosis. MRI has an excellent ability to diagnose ACL tears, with sensitivity, specificity, and accuracy all above $90 \%$. In the vast majority of cases, MRI scans reveal an ACL rupture, which is obvious based on clinical findings. fibre discontinuity is the main indicator of an ACL rupture.

Young energetic people and skeletally immature individuals find nonoperative treatment of ACL tears unappealing. Recurrent instability and the development of chondral and meniscal injuries often arise as a result of this.

Re-approximating the torn ends of the native ACL was the first documented surgical therapy for ACL tears, as described by Robson in the early 1900s, and it is done by using suture or suture anchors. Aversion to making little adjustments. Autograft or cadaver tissue may be obtained from the patient (allograft). [8].

Early ACLR may contribute to delay in quadriceps healing and may lead to a loss of range of motion. Several studies show that quadriceps strength is significantly decreased after ACLR (first seven days post-injury) when it is performed early in the recovery process as opposed to later, and also show a substantial reduction in knee extension towards the end of the recovery process. This shows that the increasing usage of preoperative rehabilitation is on the rise. Exercise before the operation is crucial because it helps preserve 
quadriceps strength and knee range of motion, both of which are important for functional results.

This research set out to comprehensively evaluate the existing research on late outcomes in the wake of ACL repair.

\section{Material and methods}

\subsection{Search strategy}

An electronic search was conducted from the inception till April 2020 in the following bibliographic databases: Medline via PubMed, SCOPUS, Cochrane Central Register of Controlled Trials (CENTRAL), and Web of Science to identify relevant articles. We used different combinations of the following queries: ((Reconstructive) OR Reconstruction)) AND ((Transplant) OR graft)) OR (Autograft) OR Autologous) OR Autotransplant)) OR ((Allograft) OR Allogeneic) OR Homograft) OR Homologous)) OR hybrid) OR ((Hamstring) OR Semitendinosus) OR Gracilis) OR Tibialis) OR Achilles) OR Calcaneal)) OR Artificial Ligament) AND (RCT[MeSH Terms]) OR RCT[Title/Abstract]) OR randomized controlled trial[Title/Abstract])) OR randomized controlled trial[MeSH Terms]).”..

\subsection{Inclusion criteria}

Studies included should meet the following criteria:

$\checkmark \quad$ Studies that included adult patients with anterior cruciate ligament (ACL) injury.

$\checkmark$ Studies that assessed the long-term results of different techniques of ACL reconstruction.

$\checkmark$ Studies that reported any of the following outcomes:

- Clinical outcome assessments (range of motion, anterior drawer test, pivot-shift test, Lachman test, and knee laxity measurements with KT1000/KT-2000 arthrometer)

- Objective functional testing (1-leg hop, stair hop, and agility tests)

- Isokinetic muscle strength testing, patientreported quantitative outcome measures (International Documentation Knee Documentation Committee [IKDC] grade, Lysholm score, Tegner activity scale)

- Radiographic evidence of OA

- Graft failures and associated complications.

$\checkmark$ Studies that were randomized controlled trials (RCTs), comparative studies, or prospective cohort studies.

$\checkmark \quad$ Human subjects and in the English language.

\subsection{Exclusion criteria}

The Studies that were excluded had any of the following features:

$\checkmark$ Reviews, conference presentations, editorials or expert opinions.

$\checkmark \quad$ Case reports \& case control studies.

$\checkmark$ No abstract.

$\checkmark$ Other knee injury (e.g. PCL or Meniscal injury).

\section{Results}

\section{- Study selection}

In the present study, we searched Medline via PubMed, SCOPUS, Web of Science, Cochrane Central Register of Controlled Trials (CENTRAL), and Google Scholar from their inception till April 2020. The search retrieved 2089 unique records. We then retained 57 potentially eligible records for full-texts screening. Finally, fifteen studies were included Figure (1).

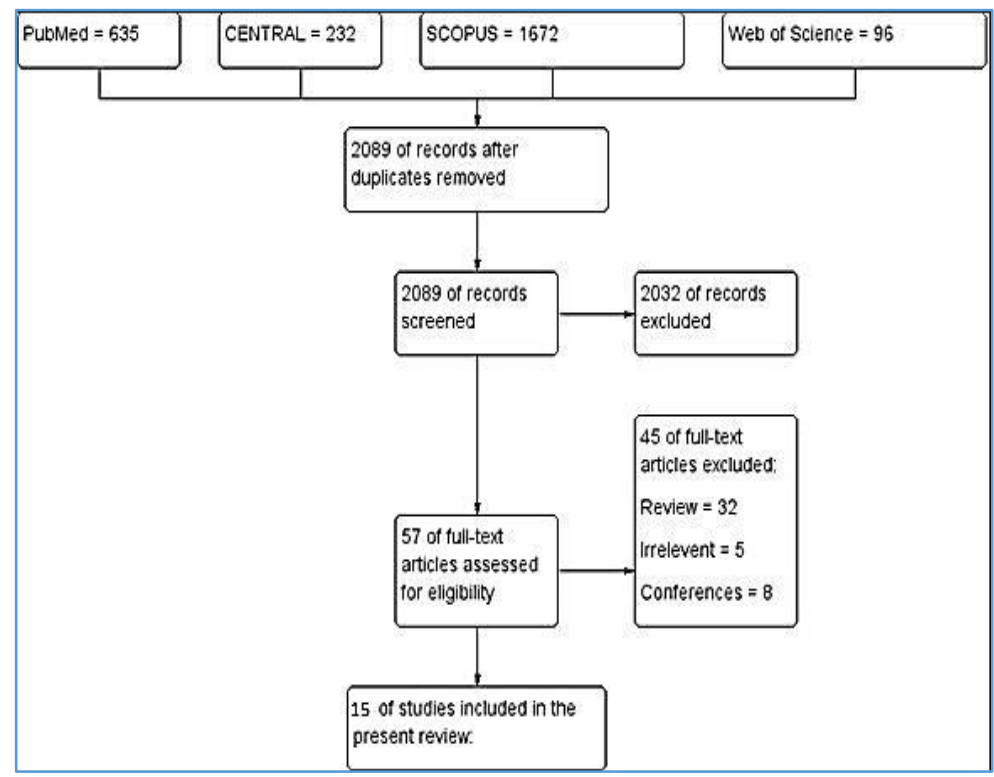

Fig. (1) Prisma flow diagram for selection included studies.

Characteristics of the Included Studies:

Table (1) Summary Characteristics of the included studies. 


\begin{tabular}{|c|c|c|c|c|c|c|c|}
\hline No. & Authors & Year & Country & $\begin{array}{l}\text { Procedure } \\
\text { Date Range }\end{array}$ & Study De sign & $\begin{array}{c}\text { Single or } \\
\text { Multice nter }\end{array}$ & $\begin{array}{l}\text { No. of } \\
\text { Patient }\end{array}$ \\
\hline 1 & O’Neill & 2001 & USA & 1989-1994 & Randomized Controlled & Single & 225 \\
\hline 2 & Ibrahim et al & 2005 & Kuwait & 1994-1996 & $\begin{array}{l}\text { Trial } \\
\text { Randomized Controlled } \\
\text { Trial }\end{array}$ & Single & 85 \\
\hline 3 & Zaffagnini et al & 2006 & Italy & 1998 & Retrospective Study & Single & 75 \\
\hline 4 & Keays et al & 2007 & Australia & & Prospective study & Single & 56 \\
\hline 5 & Lidén et al & 2007 & Sweden & 1995-1997 & $\begin{array}{l}\text { Randomized } \\
\text { Controlled Trial }\end{array}$ & Single & 68 \\
\hline 6 & Ahldén et al & 2009 & Sweden & 1995-1998 & Retrospective Study & Single & 47 \\
\hline 7 & Holm et al & 2010 & Norway & & $\begin{array}{l}\text { Randomized } \\
\text { Controlled Trial }\end{array}$ & Single & 57 \\
\hline 8 & Sajovic et al & 2011 & Slovenia & $1999-2000$ & $\begin{array}{l}\text { Randomized } \\
\text { Controlled Trial }\end{array}$ & Single & 52 \\
\hline 9 & Wipfler et al & 2011 & Germany & 1998-1999 & $\begin{array}{l}\text { Randomized } \\
\text { Controlled Trial }\end{array}$ & Single & 54 \\
\hline 10 & Leys et al & 2012 & Australia & 1993-1994 & Prospective study & Single & 94 \\
\hline 11 & Gifstad et al & 2013 & Norway & 2001-2004 & $\begin{array}{l}\text { Randomized } \\
\text { Controlled Trial }\end{array}$ & Multicenter & 93 \\
\hline 12 & Webster et al & 2016 & Australia & 1996-1998 & $\begin{array}{l}\text { Randomized } \\
\text { Controlled Trial }\end{array}$ & Single & 47 \\
\hline 13 & Beyaz et al & 2017 & Turkey & $2007-2008$ & $\begin{array}{l}\text { Randomized } \\
\text { Controlled Trial }\end{array}$ & Single & 31 \\
\hline 14 & Jarvela et al & 2017 & Finland & 2003- 2005 & $\begin{array}{l}\text { Randomized } \\
\text { Controlled Trial }\end{array}$ & Single & 60 \\
\hline 15 & Elveos et al & 2018 & Norway & $1991-1993$ & $\begin{array}{l}\text { Randomized } \\
\text { Controlled Trial }\end{array}$ & Multicenter & 100 \\
\hline
\end{tabular}

Complications Rate of the included studies:

Table (2) Complications Rate of the included studies.

\begin{tabular}{|c|c|c|c|}
\hline Authors & No.of Patients & Complications, \%(n) & Description of Complications \\
\hline Gifstad et al & 45 & $17.8(8)$ & $\begin{array}{l}6 \text { meniscus surgeries, } 1 \text { notchplasty, } 1 \\
\text { irrigation and debridement }\end{array}$ \\
\hline Holm et al & 29 & $55.2(16)$ & 16 meniscal surgeries \\
\hline Ibrahim et al & 40 & $15(6)$ & 3 meniscal injuries, 1 PCL rupture, 2 \\
\hline Keays et al & 29 & $20.7(6)$ & $\begin{array}{l}1 \text { ipsilateral PCL rupture, } 2 \text { meniscal } \\
\text { injuries, } 1 \text { asymptomatic } \\
\text { calcification in PT, } 1 \text { loose body, } 1 \\
\text { hemangioma in vastus medialis }\end{array}$ \\
\hline Lidén et al & 32 & $25(8)$ & $\begin{array}{l}1 \text { culture negative effusion, } 3 \text { meniscus } \\
\text { injuries, } 3 \text { symptomatic }\end{array}$ \\
\hline O’Neill & 150 & & NR \\
\hline Leys et al & 43 & $25.6(11)$ & $\begin{array}{l}5 \text { meniscectomies, } 2 \text { excisions of tibial } \\
\text { screw, } 1 \text { excision of patellar tendon cyst, }\end{array}$ \\
\hline Sajovic et al & 25 & $0(0)$ & NR \\
\hline Websteret & 22 & & NR \\
\hline Wipfler et al & 28 & & NR \\
\hline Zaffagnini et al & 25 & $0(0)$ & NR \\
\hline Beyaz et al & NR & NR & NR \\
\hline Jarvela et al & 32 & $53 \%$ & Osteoarthritis \\
\hline Elveos et al & NR & NR & NR \\
\hline
\end{tabular}

Failure Rate of the included studies:

Table (3) Failure Rate of the included studies. 


\begin{tabular}{lccc}
\hline Authors & $\begin{array}{c}\text { No.of } \\
\text { Patients at }\end{array}$ & No. of Failure s, \% (n) & $\begin{array}{c}\text { Cause of } \\
\text { Failure }\end{array}$ \\
\hline Gifstad et al & 45 & $4(2)$ & NR \\
Holm et al & 29 & $10(3)$ & Traumatic \\
Ibrahim et al & 40 & $0(0)$ & NR \\
Keays et al & 29 & $0(0)$ & NR \\
Lidén et al & 32 & $3(1)$ & NR \\
O'Neill1 & 150 & $5(4)$ (group II) $7(5)$ (group III) & NR \\
Leys et al & 43 & $8(7)$ & NR \\
Sajovic et al & 25 & $12(4)$ & NR \\
Webster et al & 22 & $5(1)$ & Traumatic \\
Wipfler et al & 28 & $11(3)$ & NR \\
Zaffagnini et al & 25 & $0(0)$ & NR \\
Beyaz et al & 31 & $0(0)$ & NR \\
Jarvela et al & 47 & $11(0)$ & Traumatic \\
Elveos et al & 100 & $19(0)$ & Traumatic \\
\hline
\end{tabular}

Radiographic Outcomes:

Table (4) Radiographic Outcomes.

\begin{tabular}{|c|c|c|c|c|}
\hline Authors & $\begin{array}{l}\text { No.of } \\
\text { Patients }\end{array}$ & IKDC & K-L & Obje ctive \\
\hline Ibrahim et al & 40 & NR & & Moderate OA in $35 \%$ \\
\hline Keays et al & 29 & NR & & $\begin{array}{l}\text { Mild-moderate OA in } 62 \% \text { (18) Moderate PF OA in } \\
41 \% \text { (12) }\end{array}$ \\
\hline Leys et al & 58 & \multicolumn{3}{|c|}{ Grade A: $41 \%$ (24) Grade B: $48 \%$ (28) Grade C: $10 \%$ (6) } \\
\hline Sajovic et al & 25 & \multicolumn{3}{|c|}{ Grade A: $16 \%$ (4) Grade B: $40 \%$ (10) Grade C: $44 \%$ (11) } \\
\hline Webster et al & 19 & \multicolumn{3}{|c|}{ Grade $0-1: 74 \%$ (14) Grade 2-3: 26\% (5) } \\
\hline Beyaz et al & NR & 71.29 & \multirow{2}{*}{\multicolumn{2}{|c|}{$\begin{array}{l}\text { NR } \\
\text { OA in the medial compartment of the operated } \\
\text { knee was present in } 38 \% \text { of the patients, in the lateral } \\
\text { compartment in } 38 \% \text {, and in the patellofemoral compartment } \\
\text { In } 34 \% \text {. }\end{array}$}} \\
\hline Jarvela et al & 32 & NR & & \\
\hline Elveos et al & 65 & NR & \multicolumn{2}{|c|}{$\begin{array}{l}15 \text { patients }(27 \%) \text { had severe OA: } 9 \text { of } 28(32 \%) \\
\text { in the BPTB group and } 6 \text { of } 28(21 \%) \text { in the LAD group }\end{array}$} \\
\hline
\end{tabular}

\section{Discussion}

ACL injuries are very frequent in sports medicine. An injury of this type is often seen in sportsmen or the general public who do the incorrect exercises or fitness routines. To assist in ACL recovery, patients who have been diagnosed with ACL damage are often given the option of anterior cruciate ligament repair (ACLR). The reconstructive methods were utilised during ACL repair operations.

In the short- and intermediate-term, ACLR provides impressive outcomes independent of the graft utilised. Surveys and long-term research have shown generally positive outcomes for at least 10 years following surgery. It has been observed that seven years following surgery, degenerative alterations of the cartilage may be seen. Follow-up time increases the risk.
Thus, in order to thoroughly evaluate previously published research on late ACL repair outcomes, we performed the current study.

In the current research, we looked for citations from the beginning of Medline until April 2020 in databases including PubMed, SCOPUS, Web of Science, Cochrane Central Register of Controlled Trials (CENTRAL), and Google Scholar. 2089 distinct records were found during the search. We were left with 57 possibly suitable records, of which we did fulltext searching on all of them. The final count was twelve studies.

\section{Automatic and controlled laxity}

As a general rule, the mean ROM of the general population is lower than the ROM seen in patients with generalised joint laxity (GJL). It has been shown that 
GJL and hyperextension of the knee have been linked to an increased risk of ACL damage, and it is generally recognised that this may include both non-contact and contact injuries. This past research has shown that females had higher laxity in the knee joint and increased GJL.

The Lachman test is a physical examination technique used to determine the health of the anterior cruciate ligament. The degree of laxity of the ACL is graded as mild, moderate, and severe, which corresponds to Grade 1, 2, and 3 ACL injuries. Grade I anterior tibial translation is 0 to $5 \mathrm{~mm}$, Grade II is 6 to $10 \mathrm{~mm}$, and Grade III is 11 to $15 \mathrm{~mm}$ relative to the undamaged side.

Although, theoretically, the pivot shift is the ideal test to detect and measure the health of the ACL, which is especially relevant in diagnosing ACL deficiency, evaluating treatment strategies for ACL injuries, and constructing treatment algorithms for patients with ACL injuries, there are a few complications that have to be taken into consideration. a grading system for pathologic motion seen in a pivot shift test was established by the International Knee Documentation Committee (IKDC): 0 is normal, 1 is glide, 2 is clunk, and 3 is stone-walled (locked subluxation).

The results indicate that the long-term Lachman Grade 0-1 post-ACLR rate is about 97.8 percent (95 percent confidence interval, 196-99.5 percent). Pivot Grade 0-1 following ACLR's long-term rate was estimated to be 97.8 percent (95 percent CI: $96-99.5$ percent).

Our findings concur with those of Sundemo and et al.; thus, in concurrence with these results, we examined whether postoperative knee laxity is linked with worse long-term prognosis after ACL reconstruction. Of the 193 patients who had ACL repair, $117(61.3 \%)$ were evaluated again after 2 years, while the other $82(38.7 \%)$ were checked again at 16 years. The Lachman Grade 0-1 Lachman Grade 0-1 rate was 95\% while the Pivot Grade 0-1 Pivot Grade 01 rate was $96 \%$.

In contrast to a group of non-operatively treated individuals, clinical and radiological outcomes for patients who had had ACL reconstruction were evaluated by Mihelic and et al. After 15-20 years, individuals who had ACL repair demonstrated that $94 \%$ of them remained stable in their knees.

The clinical and scientific communities have both used instrumented knee laxity testing equipment to assess individuals with knee injury. Knee motion quantification may improve clinical practise and research, since it would make knee-ligament damage more precisely and reproducibly measurable.

In our meta-analysis, the overall impact estimates were 1.2 (95\% confidence interval [CI] 0.89 to 1.6 ).

Just as we found, Mouarbes and colleagues conducted a comprehensive literature search on clinical trials related to ACL repair. In all, there were 2856 individuals having ACL repair in 27 clinical trials that fulfilled the inclusion criteria. The side-to-side mean difference of instrumented means was 0.9 [6].

\section{Patients' experience}

In addition to clinical examination, patient-reported measures of knee function are essential for complete evaluation of ACL status. The International Knee Documentation Committee (IKDC) subjective selfevaluation of functional level and symptom-related impairment is responsive, trustworthy, and valid. This questionnaire tests how well the patient describes their level of function and symptoms when engaged in everyday activities, and how active they are in sports.

While on the other hand, research has shown the Lysholm knee score's usefulness in functional assessment for different knee ailments, including patellofemoral pain syndrome, meniscal injuries, and other chondral diseases.

The impact estimates we obtained indicated that the IKDC score A rate was 55.4\% (95\% CI 42.7-68.2\%). IKDC rate $\mathrm{B}$ is estimated to be $37.3 \%$ (95\% CI: $24-$ $50.6 \%$ ). Based on Lysholm knee data, the mean Lysholm score was estimated to be 87.085 (95\% confidence interval [CI] 84.4-89.7).

In agreement with our results, Jia and et al. found that the Ligament Advanced Reinforcement System (LARS) artificial ligament provided long-term clinical benefits after ACL repair. We have 168 patients in our practise who had arthroscopic ACL repair done with the LARS artificial ligament. The pre- and postoperative Lysholm scores increased from $54.6 \pm$ 14.3 to $85.4 \pm 12.1$ [10].

For this study, Al-Khalifa \& et al. analysed data from 36 patients with an ACL repair to determine their functional results two years after surgery, who received hamstring autografts. Approximately $97.2 \%$ (35/36) of the subjects had a normal or very normal clinical assessment. Severe passive motion deficit was found to be mild to practically normal in $97.2 \%$ (35/36). Nearly all patients (94.4 percent) showed normal or near normal compartmental results, and nearly all patients (34/36) had normal or near normal clinical manual knee ligament findings.

The failure rate and complications of treatment

There are both short-term and long-term problems with this surgery.

Failure rate was found to vary from $0-10 \%$, while complication rate was found to range from $8-11 \%$. Meniscus operations, notchplasty, irrigation, and debridement were the most often performed procedures.

\section{Conclusion}

A total of 12 investigations revealed that Lachman Grade 0-1 (most severe) after ACLR results in a 97.8 percent success rate, and Pivot Grade 0-1 (most severe) after ACLR results in a 97.8 percent success rate. Prior to surgery, the Lysholm score had been at an insufficient level.

\section{References}


[1] B.Barenius, S.Ponzer, A.Shalabi, Increased risk of osteoarthritis after anterior cruciate ligament reconstruction: a 14-year follow-up study of a randomized controlled trial. Am J Sports Med. vol.42(5),pp.1049-57,2014

[2] M. Purnell, A. Larson, and W. Clancy, Anterior Cruciate Ligament Insertions on the Tibia and Femur and Their Relationships to Critical Bony Landmarks Using High-Resolution VolumeRendering Computed Tomography. Am J Sports Med November vol. 36,pp.2083-2090,2008.

[3] M.Sakane, R. Fox , S. Glen,A. Livesay, In situ forces in the anterior cruciate ligament and its bundles in response to anterior tibial loads. Journal of Orthopaedic Research. vol. 15(2),pp.285-93,1997.

[4] S.Kim ,J.Bosque ,J. Meehan ,A. Jamali ,R. Marder, Increase in outpatient knee arthroscopy in the United States: a comparison of National Surveys of Ambulatory Surgery, 1996 and 2006. J Bone Joint Surg [Am]vol.93-A,pp.9941000,2011

[5] A. Benjaminse ,A. Gokeler,C. van der Schans ,Clinical diagnosis of an anterior cruciate ligament rupture: a meta-analysis J Orthop Sports Phys Ther, vol.36 (5), pp.267-288,2006.

[6] R.Frobell, L. Lohmander,H. Roos, Acute rotational trauma to the knee: poor agreement between clinical assessment and magnetic resonance imaging findings. Scand J Med Sci Sports. vol.17(2),pp.109-114,2007

[7] A.Ajuied ,F. Wong ,C. Smith ,M. Norris ,P. Earnshaw, D. Back, Anterior cruciate ligament injury and radiologic progression of knee osteoarthritis: A systematic review and metaanalysis,vol.125,pp.947-950,2014

[8] A.Kiapour , M. Murray, Basic science of anterior cruciate ligament injury and repair. Bone Joint Res.vol.3,pp.20-31,2014

[9] N.Paschos ,S. Howell ,Anterior cruciate ligament reconstruction: principles of treatment. EFORT Open Rev.vol.1(11),pp.398-408,2016

[10] A. Rahnemai-Azar ,S. Sabzevari,S. Irarrázaval ,T. Chao , Anatomical individualized ACL reconstruction. Arch Bone Joint Surg,vol.4,pp.291-7,2016. 